\title{
Introduction: Let's Talk About (Crip) Sex
}

\section{Tomasz Sikora Dominika Ferens}

The intention of this special thematic issue of InterAlia is to problematize the notion of a healthy, (re)productive, desirable body through the lenses of queer and crip theory. The perspective we adopted when calling this issue into existence was largely a continuation of the one proposed in a provocative article by Paulina Szkudlarek and Sławomira Raczyńska entitled "Zboczone kaleki. Poza sanonormatywnością i somatoestetyką" (Perverted Cripples. Beyond Sanonormativity and Somaaesthetics). The thrust of the argument was that illness and disability in conjunction with nonnormative sexualities has the potential to (doubly) undermine the liberal-humanist model of modern subjectivity, although more often than not the dominant, neoliberal, politically correct discourses effectively separate the two "parameters of identity" without ever acknowledging how fluid and intersecting they are in a single body - a body whose ever changing processes, needs and desires can never reduce it to a stable, self-contained unit. Such regulation of non-normative sexual bodies is mostly achieved through, on the one hand, relegating disabilities to the sphere of medical management and personal "success" through determination and hard work, and, on the other, tabooing the sexual (let alone queer sexual) in the disabled person's experience, while often reinforcing normative gender roles and rules of attractiveness. Disabled people's sexuality is regarded as also somehow disabled, and if recognized at all, it becomes - in countries with highly developed social welfare systems - a "problem" to be remedied by, for example, providing the cripples with sex-workers. To counter this imposed neoliberal framework, complete with the "individual rights" emancipatory narrative, Szkudlarek and Raczyńska argue for much more "rebellious" queer/crip interventions: they embrace kinky cripples rather than the socially and medically corrected approximations of the healthy-bodied - and hence fully (hetero)sexual Vitruvian Man.

All too often research on the intersection between disability and sexuality is more or less overtly indebted to the long "ethnographic" tradition in that it could be collected under the general rubric: 
"The Sexual Life of Cripples in Western (Neo)Liberal Societies." Even the turn towards unique personal accounts of the so-called marginalized groups - as in standpoint theory - does not necessarily break away from that tradition. It seems progressive and open-minded to "give a voice" to the subalterns as if it were tantamount to giving them (more) subjectivity and agency, but multiple questions arise at once: Who has the privilege of giving or not giving a voice? How are the received accounts fitted into dominant (academic and non-academic) discourses? Which of the accounts are preferred and why? How are techniques of normalization and self-normalization operating in such personal accounts, and to what extent are they always-already implied in the interaction between an "academic" and a "subject"? How is the crip subject always-already interpellated in a way that leaves little room for self-fashioning and becoming? The questions could go on and on. Arguably, the starting point in such approaches is the idea of lack or deficiency, no doubt related to the medical practice of measuring the degree of disability by determining what percent of an average "healthy" ability the disabled person can achieve or what is the calculable percentage of health loss. We fundamentally disagree with such methodologies and instead postulate an ontology that looks at bodies, including bodies categorized as crippled, with no use for inherent normative measurements and hierarchizations. In other words, the so-called "disabled" body is ontologically equal to any other body in how it finds ways to live and act and develop. It is a body complete in its own embodiment - as much, of course, as any body can be considered complete in its continuous processes of (un)becoming and its complex exchanges with the environment. If anything, "disabled" bodies may be much more revealing about the ontological status of the human and non-human bodies in general in that they register more clearly both the vulnerabilities innate to any living body and the variable capacities and adaptations it develops in response to its environment. It is a commonplace, after all, to say that the history of every single body includes at least some periods of disability, starting with infancy, through temporal or lifelong illnesses and injuries, all the way up to old-age impairments, which demonstrates the absurdity of constructing the "disabled" as a separate, identity-based group of people. Instead, we believe it is through the adaptational richness and the acquisition of certain "over-abilities" that crippled bodies should be looked at. Not: what this or that body cannot do compared to other bodies, but precisely what this or that body can do in its singular conatus. And sexuality, to be sure, is one of the spheres where the body's ability to explore its own capacity for pleasure and pain (where the two can sometimes uncannily overlap), discover new sensations and invent new erotic practices is most intensely tested out. 
A similar logic applies to the question of the supposed "unnaturalness" of certain bodies. Able and healthy bodies are commonly connoted as "natural" (which further connotes "natural," i.e. straight sexuality), whereas disabled bodies, which often can only function due to some medical intervention, are consequently considered less "natural." The crip ontology we envisage starts precisely from the technologies and techniques on which any body vitally depends - a perspective that is now being developed under the name of somatechnics. ${ }^{1}$ Life and life activities always depend on a complex network of life-supporting systems, both within and without a single organism. The mediation of technology (as when certain animals use a stick to extend their "natural" abilities, or when life-saving equipment is connected to a patient) as well as the acquisition of techniques (as when an animal/human learns to swim or to move around without legs) are inscribed in any embodied existence - no less for "healthy" bodies as for the bodies with what are perceived as handicaps. In other words, it is important to see cripples' abilities not as fundamentally limited and conditionally extended despite their handicaps, but to see the handicaps as occasions for the actualization of virtual abilities that able bodies will never have access to. Bodies can be bodies only insofar as they learn their ways in a given environment. Let us be clear, however: fully acknowledging crippled bodies' ability to expand their abilities is no excuse for the failing to reshape physical infrastructures in order to make them more liveable for those bodies which were, by default, excluded from the shared public spaces at the stage of designing and construction. Here again the "problematic" bodies help literally de-construct the ablist assumptions behind traditional architecture, just as they help deconstruct the presumptions about what "ability" means in the first place and what is "natural" about (always-already somatechnically mediated) bodies.

The phrase "ugly bodies" in the of title this issue refers to all kinds of unsightly, non-normative bodies: disabled, queer, gender-bent, trans* , fat, self-modified, racialized, aged, decrepit, deformed, and in many cases marked with various "defects" combined. Such deviant bodies are perceived as embarrassing at best, obnoxious at worst. More: they are "bodies out of place," so to speak, essentially improper, if not outright dangerous, always posing a threat to the established order of things through the sheer fact of their very existence. If not properly contained through

\footnotetext{
${ }^{1}$ For the origin of the term, see the Somatechnics blog: https://somatechnics.wordpress.com/aboutsomatechnics. So far the initiative has yielded a series of somatechnics conferences and a number of books, the most "foundational" of which is Somatechnics: Queering the Technologisation of Bodies (ed. Samantha Murray and Nikki Sullivan, Routledge, 2009).
} 
institutionalization and the mechanisms of social stigma, the (il)logic goes, such bodily deviancy could become contagious to the healthy and productive (social) body that must be protected. The etymology of the word "ugly" confirms its relation to the concepts of dreadful, fearful and even hateful, which clearly situates its connotations far beyond the concept of simply "unpleasant to look at" and closer to the more visceral idea of the repulsive and dangerous. Posited as dysfunctional in one way or another, ugly bodies become even more scarily grotesque when they claim sexual agency: in order to "stay where their place is" rather than spread uncontrollably like an epidemic, they must remain undesiring and undesirable bodies. This is, again, where the connection between sexuality and disability proves to be a powerful site of critique and a possible springboard for social action. From a queer perspective it is not about integration, rights and personal success, it is about being complete in one's own embodiment, which is as intimately bound up with desires and sexual pleasures, as it is with pains and physical limitations.

The disability/sexuality nexus is best understood as a vital onto-political and ethical question. Queer critiques of the dominant disability discourse, and especially its complete failure to account for the richness and queerness of the flows of desire and the actual sexual practices occurring in the complex networks that involve disabled bodies, must work towards destabilizing and, ultimately, dismantling the (neo)liberal, individualistic, politically correct language that frames much of the research and public discourse. Robert McRuer describes his project of Crip Theory as an effort "to counter neoliberalism and access alternative ways of being" (42), now severely restricted and regulated. A world that allows alternative ways of being - whether non-identitarian or quasiidentitarian or intersectionally identitarian or any other - requires a different, postconventional (to borrow Margrit Shildrick's term) ethics. One possible form of such ethics commensurate with crip studies and crip practices could be called an "ethics of life-supporting systems." In terms of natural/social ecosystesms (the two never separable) no life exists on its own: it always depends on the infrastructures of the physical world, protection, and care. As Paul K. Longmore noticed long ago, the self-developed disability culture (just like, arguably, non-neoliberalized queer culture) emphasizes "not independence but interdependence, not functional separateness but personal connection, not physical autonomy but human community" (9). One must also be aware of how life-supporting infrastructures are always a (bio)political question as well, referring us ultimately to the question of the structural distribution of the "good life" in present-day societies; yet this is a line of investigation that merits a separate issue of InterAlia. 
As often happens when journals announce thematic issues, some of the submitted articles do not respond directly to the questions raised in the Call for Papers; nor do they necessarily use the suggested theoretical tools and methodologies. But the response to our call for papers was more than gratifying because each author contributed to queer and disability studies stimulating work driven by research questions that arose out of his or her own experience and knowledge questions that we from our local perspective would not have thought to pose.

For practical reasons, the editors have decided to divide the issue into two parts, one that collects submissions in English, and the other one (to be published shortly after) - texts in Polish.

The Polish part opens with a translation of an article by Robert McRuer, the initiator of Crip Studies as a field of investigation that combines radical thinking on disability with queer approaches to sexuality. The article is a continuation of and elaboration on McRuer's earlier reflections in his ground-breaking book Crip Theory: Cultural Signs of Queerness and Disability (2006). A similarly broad theoretical perspective in the English part of the issue is provided by the philosopher Thomas Abrams' contribution "Disability, Queer Phenomenology and the Political Economy of Personhood," where Abrams engages in a dialogue with Sara Ahmed's influential book Queer Phenomenology (2006). While Ahmed brings together the categories of race and desire, Abrams advocates employing her approach for considering the material experience of disability and the formation of "disabled" subjectivities.

Both parts of the Ugly Bodies issue contain sociological perspectives. Drawing on six years of fieldwork carried out in Polish escort agencies, Izabela Ślęzak implicitly asks: How can the sexual needs of men with disabilities be met if the sex-workers they seek out overwhelmingly reject them? And to what extent does the sex-workers' attitude reflect the dehumanization and desexualization of disabled men by the society at large? Although the article refers to the therapeutic practices propagated by the International Professional Surrogates' Association, it stops short of proposing such solutions in Poland, perhaps because of the abrupt conservative turn towards the end of 2015. Nonetheless, Ślęzak draws attention to the urgent need to address disability and sexuality together, not just within academia but more importantly - outside it. Ślęzak's concerns dovetail with those 
voiced in "Against the Ugliness of Age: Towards an Erotics of the Aging Sexual Body" by Alison Moore and Paul Reynolds in the present issue.

The sociological method in research on non-normative sexualities is represented in the English part of the present issue by the article entitled "Intersectionalities, Dis/abilities and Subjectification in Deaf LGBT People." On the basis of interviews concerning the experiences of deaf LGBT youth in Sicily, the psychologist Claudio Cappotto and sociologist Cirus Rinaldi set out to prove how necessary it is to rigorously apply the intersectional approach in qualitative research. Of special interest are the voices of young people who belong to a very non-standard minority group. As the interviews demonstrate, they had so far been perceived by teachers, medical staff and researches solely in terms of the hearing impairment and never asked how they coped in a heterosexist society.

The intersectional approach is also applied in Marta Usiekniewicz's article on obesity, race and class in the US. Starting from the cases of fat black men getting killed by policemen or by selfappointed law-enforces, Usiekniewicz analyzes the ideological underpinning of the criminalization of black male obesity in the US and points out the limitations of much of Fat Studies that concentrates mostly on the experiences of white women.

Ugliness is attributed to those bodies that deviate from a given society's norms due to motor disability, hearing impairment, skin color, obesity, among many others. As Oindri Roy and Amith Kumar demonstrate in their contribution, persons deviating from the norms of proper male and female looks are also commonly perceived as ugly. The daily lives of transgender people in India, as described in autobiographical writing, are the point of departure for theoretical considerations. The authors investigate two autobiographies: The Truth About Me: A Hijra Life-Story (2010) by the Indian transgender activist A. Revathi, and A Queer and Pleasant Danger (2012) by American gender rebellion icon, Kate Bornstein.

Two articles by Polish authors Hubert Zięba and Rafał Syska, look closely at the ways in which Hollywood and art-house film directors deploy "ugly" - diseased, zombified, and transgendered bodies. Drawing on Susan Sontag's work on illness as metaphor, Zięba critiques large postapocalyptic film productions like World War $Z$, that map plagues reminiscent of AIDS onto a 
global geography, and link them with immorality, homosexuality, and non-whiteness. Consequently, as Zięba points out, within the logic of these films, the transnational zombie/AIDS plague can only be eradicated by the virtuous white heterosexual American male. Thus, to use Judith Butler's formulation from Frames of War, films like World War Z perpetuate the "social norms that allow certain populations to emerge as living beings and others to be considered as nonliving, or as only partially living, or as threats to the living." In his contribution, Rafał Syska fills a gap in film criticism by placing Container within a line of Western films about transsexuality and goes on to demonstrate Containter's uniqueness as an experimental film that uses a wide range of visual, aural, and narrative techniques to explore the interiority of psycho-sexual difference. Unlike the diseased bodies on a rampage in World War $Z$, the "ugly" male body that conceals a "beautiful" female subjectivity is not a "threat to the living," because it is locked within a claustrophobic "container" and focused inwards, on memories/ hallucinations. Whether Moodysson's vision of the "ugly body" as forever doomed can lead to a "recognition of my life being like another's life" is debatable. Nonetheless, its rendition of psychological depth may make it difficult for the viewer to see transsexuals as "non-living, or as only partially living" (to quote Butler once more).

Subjectivity likewise organizes Anna Filipowicz's discussion of the tenuous and troublesome connection between human flesh and the prosthesis, "From Campy Burlesque to (Post)constructivist Performance: On Wearing Dentures in the Poetry of Miron Białoszewski." Had we published the Polish- and English-language texts in one volume, we would have paired up Filipowicz's nuanced poetry analysis with Allison Moore's and Paul Reynolds's "Against the Ugliness of Age: Towards an Erotics of the Aging Sexual Body." Although Moore and Reynolds write from a sociological perspective to rescue ageing and disabled bodies from being perceived as grotesque, while in Filipowicz's account of the ageing poet Białoszewski wallows in the grotesque, coming to terms with his dentures as an impediment to eating and lovemaking, they all insist: old people just want to have fun!

Last but not least, we decided to include in the Polish-language section of the Ugly Bodies issue a Polish translation of the article "Uncanny Erotics - On Hans Bellmer's Souvenirs of the Doll" by Jeremy Bell. The text offers an interpretation of the work of Hans Bellmer, modernist artist and writer. Bellmer worked mostly in France, where he gained recognition thanks to his surrealistic installations and photographs of dolls. Their bodies, made of different materials, dismembered and 
recombined into articulated assemblages, evoke both suffering and desire, which leads Bell to reflections on eroticism, corporeality, power and gender identity. Adhering to the psychoanalytical method, the author refutes the claims that Bellmer's work is characterized by misogyny and an essentialized gender binary. Although Bell's text does not address disability directly, it is an example of how the question of the relationship between functional/dysfunctional/prosthetic /unnatural bodies and sexual pleasure/pain/desire can be innovatively rethought through art.

The English-language part of the current InterAlia issue also includes a small non-thematic section, consisting of two contributions. By looking closely at the poetry of Marilyn Hacker and Carl Phillips, Jason Bryant examines the performativity and self-reflexivity of "queer coupling." The important methodological distinction that Bryant makes is the one between (homo)normative love and marriage narratives and alternative, queer ways of doing intimacy, domesticity and partnered relationships. Due to their particular and never unproblematic positioning in relation to power, norm and desire, queer subjects develop, or should develop, a "queer sensitivity" that is alert to the complexities of queer relations.

Stanimir Panayotov's statement, which reads almost like a manifesto, targets what he calls "straight separatism" defined as "the culture of self-assimilation in the forms of institutionality and memorialization." At a time when creating and working with "queer archives" is increasingly regarded by many queer scholars and activists as imperative, Panayotov boldly claims that any institutional memorization is always already implicated in the identitarian, heterosexual paradigm of love and recognition that inevitably leads to universalization, assimilation and the debilitation of difference through the apparent act of embracing it. As a result, queers must "abandon all forms of remembrance," at least those forms that depend on institutionalization and formalization.

The two non-thematic pieces can, in fact, be read dialogically vis-à-vis the articles collected for the thematic part. The queer forms of relationship-making explored by Jason Bryant can easily include questions of illness, disability or ageing and how they feature the "queer sensitivity" he describes. On the other hand, the way Panayotov's contribution methodologically challenges many of the prevalent discourses on queer sexuality might be productively applied to discourses on disability as 
well. The question might be: Is crip archiving the direction to go now, or should we know better, taught by decades of queer critique?

The editors would like to thank Paulina Szkudlarek for her invaluable contribution in the initial stages of to putting the Ugly Bodies issue together. She authored the very idea of this thematic issue and composed much of the Call for Papers. She also helped in the selection of the submitted articles and was consulted on several occasions during the editorial process.

\section{Works Cited}

Longmore, Paul K. "The Second Phase: From Disability Rights to Disability Culture." The Disability Rag, September/October, 1995. 4-11

Butler, Judith. "Frames of War." Hegel-Lecture II delivered at Dahlem Humanities Center, Freie Universität, Berlin. 3 Feb. 2009. <http://www.fu-berlin.de/sites/dhc/audio/index.html>. Retrieved July 20, 2009.

McRuer, Robert. Crip Theory: Cultural Signs of Queerness and Disability. NYU Press, 2006. 